\title{
Relações entre coletivos com as Jornadas de Junho
}

Olívia Cristina Perez ${ }^{1}$ (iD

\begin{abstract}
Este artigo aborda organizações políticas denominadas coletivos e suas relações com o ciclo de protestos conhecido como Jornadas de Junho de 2013. Na pesquisa exploratória foram entrevistados membros de 21 coletivos da cidade de Teresina e sistematizadas informações de 725 páginas de coletivos cadastradas na rede social Facebook. Os resultados indicam que os coletivos foram criados principalmente nos últimos seis anos, sendo que membros de alguns deles conheceram a forma de organização política do tipo coletivo depois das Jornadas. Além dessa relação, os coletivos criticam partidos políticos e organizações tradicionais pela presença de hierarquias e ineficiência, críticas também presentes nas Jornadas. Justamente para se contraporem a esse modelo de organização política, alguns coletivos defendem práticas mais autônomas e horizontais. Para que se entenda a emergência de organizações após os protestos, são retomadas reflexões de teóricos dos movimentos sociais. O texto contribui com os estudos sobre mobilizações sociais ao analisar legados das Jornadas, como o incentivo aos coletivos.
\end{abstract}

Palavras-chave: coletivos; Jornadas de Junho; antipartidarismo

\section{Introdução}

Este artigo examina os chamados coletivos e suas relações com o ciclo de protestos identificado como Jornadas de Junho de 2013. Embora seja uma nomenclatura bastante presente, são poucos os estudos que tratam especificamente dos coletivos: alguns deles são brasileiros (Mesquita, 2008; Borelli e Aboboreira, 2011; Siqueira e Lago, 2012; Costa e Paulon, 2012; Maia, 2013; Ferreira, 2015; Amador e Castro, 2016; Gohn, 2017), outros da Venezuela (Saprieza, 2015), Chile (Mora e Rios, 2009), Índia (Desouza, 2012) e Estados Unidos (Bordt, 1990; Valk, 2002). Tais trabalhos pontuam algumas das características dos coletivos, como a fluidez, a horizontalidade e a ação múltipla e pontual. Outros trabalhos (Vommaro, 2015; Augusto, Rosa e Resende, 2016; Gohn, 2018; Tatagiba e Galvão, 2019) exploram protestos e participação política, abordando também os coletivos.

Os coletivos participaram das chamadas Jornadas de Junho (Vommaro, 2015;

\footnotetext{
1 Universidade Federal do Piauí, Programa de Pós-Graduação em Ciência Política. Teresina (PI), Brasil. E-mail: <oliviacperez@yahoo.com.br>.

${ }^{2}$ Agradeço ao grupo de pesquisa "Democracia e marcadores sociais da diferença" pelo auxílio na coleta e sistematização dos dados. Agradeço também aos excelentes comentários dos pareceristas da revista Opinião Pública.
} 
Tatagiba e Galvão, 2019), as quais podem ser entendidas como um ciclo de protestos que se espalharam pelo Brasil em meados de 2013, embora não seja possível associar as Jornadas a um único protesto, pauta ou ator. As Jornadas reuniram diversas questões, tanto demandas de direitos sociais quanto críticas ao sistema político. Parte dos manifestantes foi inclusive hostil à presença de partidos e de seus militantes (Tatagiba, 2014). Ainda que os protestos não tenham se limitado a 2013, esse texto se concentra naquele período, pois foi ele o referenciado por membros de coletivos como o momento em que Ihes foi oferecida a oportunidade de conhecerem organizações do tipo "coletivos".

Em comum, coletivos e manifestantes que estavam nas Jornadas têm o fato de expressarem críticas ao sistema político parlamentar, o que já indica uma relação entre eles. Ademais, embora não seja possível afirmar que os coletivos foram criados a partir de 2013, houve um notável crescimento destes depois das Jornadas.

A relação entre protestos e formação de organizações políticas pode ser compreendida a partir dos ensinamentos dos teóricos dos movimentos sociais. Um dos principais representantes da teoria dos novos movimentos sociais, Melucci (1989), define analiticamente um movimento social como uma forma de ação coletiva baseada em conflito (relação entre atores opostos, lutando pelos mesmos recursos aos quais ambos dão um valor), solidariedade (a capacidade de os atores partilharem uma identidade coletiva) e rompimento de limites (pois rompem os limites do sistema em que ocorre a ação). Notase que, para o autor, as ações coletivas são heterogêneas, ou seja, são múltiplas, variáveis e entrelaçam heranças do passado com particularidades do presente (Melucci, 2001).

Seriam próprios aos movimentos sociais certos momentos de latência - aqueles em que as pessoas que participam dos movimentos experimentam e reinventam novos modelos culturais. Essa fase seria distinta do momento da visibilidade - em que os movimentos demonstram, por meio da mobilização pública, a possibilidade de modelos culturais alternativos. Esses dois momentos são reciprocamente correlacionados, pois a latência alimenta e permite a visibilidade, enquanto a visibilidade renova a solidariedade, facilitando a criação de novos grupos e o recrutamento de militantes (Melucci, 1989).

No mesmo sentido, conforme outra perspectiva, a da teoria do confronto político, os movimentos sociais não podem ser considerados atores homogêneos, segundo um olhar que desconsidere tanto as manobras e realinhamentos que sempre ocorrem no interior deles quanto a interação entre ativistas, componentes, alvos, autoridades, aliados, rivais, inimigos, que constituem a textura cambiante dos movimentos sociais (Tilly, 2010).

A literatura sobre confronto político também ajuda a entender a relação entre os ciclos de confronto e a emergência de movimentos sociais. Tarrow (2009, p. 25) explica que os ciclos de confrontos acontecem "uma vez que os recursos para uma ação coletiva se tornam disponíveis para as pessoas comuns e para as pessoas que diziam representálas (...) produzindo os períodos de turbulência e reorganização". Quando iniciado o ciclo, há uma redução dos custos da ação coletiva para outros atores e uma difusão dos quadros interpretativos e de modelos de ativismo. Ou seja, os ciclos de confrontos incentivam mais 
mobilização social e difundem modos de ativismo. Logo, os efeitos do ciclo vão muito além dos objetivos visíveis do movimento: "eles deixam atrás de si uma ampliação permanente na participação, na cultura popular e na sua ideologia" (Tarrow, 2009, p. 25).

Nesse sentido, conforme estudos sobre as Jornadas no Brasil (Perruso, 2014; Bringel e Pleyers, 2015), elas não tiveram impacto somente no sistema político institucional ou eleitoral, mas, de forma ampla, suas manifestações contribuíram para uma reconfiguração do ativismo social. Junho de 2013 incentivou novos atores a se organizarem politicamente utilizando discursos e repertórios aprendidos nas Jornadas.

Com base nesses apontamentos, o artigo parte das seguintes perguntas: os coletivos poderiam ser um desses atores organizados depois das Jornadas? Se sim, qual a relação entre o crescimento de coletivos com as Jornadas de Junho? O objetivo deste artigo é analisar se a formação de coletivos aconteceu depois das Jornadas e qual a relação entre esses dois fenômenos.

A análise dessa relação ocorre por meio de entrevistas com membros de coletivos que citam as Jornadas e de dados sobre o ano de criação dos coletivos cadastrados no Facebook. O discurso de membros de coletivos revela críticas ao governo e aos partidos que também se fizeram notar em Junho de 2013. A análise de conteúdo é uma técnica bastante utilizada nas pesquisas qualitativas com o objetivo de verificar a frequência com que ocorrem determinadas construções em um texto, permitindo assim sistematizar as informações reunidas (Bardin, 2006).

Para tornar compreensível a relação entre os coletivos e as Jornadas, na primeira seção deste artigo, intitulada "A diversidade nas Jornadas de Junho", certos aspectos de alguns trabalhos acadêmicos que versam sobre os protestos são expostos. Procurou-se destacar nos trabalhos informações que dão mostras de um discurso antipartidarista e antissistema expresso nas Jornadas que também fosse reproduzido pelos coletivos.

A segunda seção, "Os coletivos e a descrença nos partidos", apresenta dados empíricos sobre os coletivos. Para saber sobre a sua criação, foram coletadas informações de todos os coletivos cadastrados na rede social digital Facebook. A pesquisa buscou o descritor "coletivo" e "coletiva"3 no campo de busca do Facebook no mês de junho de 2017. O banco de dados foi formado por 725 páginas de coletivos.

Os dados da internet foram insuficientes para compreender o surgimento dos coletivos. Por isso optou-se pela realização de 21 entrevistas qualitativas com membros de todas as organizações que se denominavam coletivos em Teresina, capital do estado do Piauí. Logo, a análise central do presente artigo - a relação entre a formação dos coletivos e as Jornadas de Junho - foi baseada em entrevistas qualitativas semiestruturadas.

Para selecionar os objetos de pesquisa que seriam entrevistados, partiu-se da autodefinição das organizações como coletivos. A localização destes foi feita por meio da técnica conhecida como snowball: os entrevistados eram solicitados a indicar outros

\footnotetext{
3 A busca abarcou também o termo "coletiva", pois as entrevistas revelaram que alguns coletivos feministas por vezes adotam esse nome, reafirmando assim a questão de gênero.
} 
coletivos, até que as indicações não revelassem novos nomes. Foram localizados 21 coletivos.

Embora os nomes das organizações e de seus membros não sejam citados, conforme combinado com os entrevistados, seguem caracterizações dos 21 coletivos e as letras utilizadas para identificá-los no decorrer do texto: 16 coletivos eram formados por estudantes do ensino superior que atuavam por mais direitos dentro de duas universidades públicas. Dentre eles, quatro defendiam questões relacionadas às juventudes (identificados pelas letras $A, B, C$ e $D$ ), três defendiam os direitos das mulheres ( $E, F$ e $G$ ), três, o direito à cidade $(\mathrm{H}, \mathrm{I}$ e $\mathrm{J})$, um, o direito dos negros $(\mathrm{K})$, dois, o de lésbicas, gays, bissexuais, travestis e transgêneros (conhecidos pela sigla LGBTT), identificados pelas letras $L$ e $M$, um era anticapitalista $(N)$, um, anarquista $(O)$ e um defendia o meio ambiente $(P)$. Dentre os coletivos entrevistados, sete eram ligados a partidos políticos: Partido Socialismo e Liberdade (PSOL), Partido Comunista Revolucionário (PCR), Partido Comunista do Brasil (PCdoB) e Partido Comunista Brasileiro (PCB) (coletivos do A ao G). A luta por mais direitos para mulheres e LGBTT também era a principal preocupação de outros três coletivos que não atuavam na universidade (letras $\mathrm{Q}, \mathrm{R}$ e $\mathrm{S}$ ). Mais distantes dessas discussões, dois coletivos eram formados por artistas e não tinham uma ligação explícita com a universidade ( $\mathrm{T}$ e U). Quanto ao tamanho deles: 15 coletivos tinham de 3 a 15 integrantes; enquanto outros seis tinham entre 40 e 50 participantes. O tamanho não tinha relação com a temática. Em quase todos os coletivos apenas um membro foi entrevistado, geralmente aquele apontado por outros coletivos. Certo coletivo preferiu que a entrevista fosse realizada com todos os cinco integrantes. Das informações coletadas, foram selecionados para o presente artigo trechos das entrevistas que versavam sobre como os membros entraram em contato com essa forma de organização política, assim como a opinião sobre partidos e política.

Ao discutir o que são os coletivos, a segunda seção problematiza algumas generalizações atribuídas a eles, como o fato de serem autônomos e horizontais. Com base nos ensinamentos dos teóricos dos movimentos sociais (Melucci, 2001; Tilly, 2010), essas reflexões têm como intenção problematizar uma visão homogeneizante desses atores, apontando para um dos traços que tornam os coletivos mais interessantes: sua diversidade.

A partir desse conjunto de informações, na terceira seção são elencadas algumas relações entre o crescimento dos coletivos e as Jornadas de Junho de 2013, tanto aquelas reveladas pelas entrevistas quanto os pontos em comum entre o discurso dos entrevistados e as pautas dos protestos de 2013. Seguem-se as conclusões.

\section{A diversidade nas Jornadas de Junho}

As manifestações que se espalharam pelas ruas do Brasil em 2013 são chamadas de Manifestações de 2013, Jornadas de Junho, Junho de 2013 ou Revoltas de 2013. Os 
protestos aconteceram em diversas partes do país, embora "as lógicas de mobilização, a composição social dos manifestantes e a correlação de forças tenham variado consideravelmente dependendo das cidades analisadas" (Bringel e Pleyers, 2015, p. 7).

Ainda que tenham ocorrido em várias partes do país e nem sempre em Junho de 2013, as Jornadas são comumente associadas a um dos seus principais protestos: aquele iniciado pelo Movimento Passe Livre (MPL), que reivindicava que a tarifa do transporte coletivo na cidade de São Paulo não sofresse aumento. Há uma certa identificação dos atores que participaram dos protestos em 2013 como sendo parecidos com o MPL, considerados autônomos e horizontais no modo de decisão (Augusto, Rosa e Resende, 2016), ainda que essas características sejam passíveis de problematizações.

A identificação das Jornadas com os eventos que ocorreram em São Paulo e no Rio de Janeiro revela uma visão sudestecêntrica já contestada pela literatura (Tavares, Roriz e Oliveira, 2016). Inclusive, as passeatas de 2013 não foram bem uma novidade: os brasileiros já estavam expressando insatisfação com a política e com os serviços públicos em protestos como a "Revolta do Buzú" (Salvador, 2003) e a "Revolta da Catraca" (Florianópolis, 2004-2005), embora em 2013 tenha havido um pico dos protestos, conforme trabalho de Tatagiba e Galvão (2019).

Embora não haja trabalhos sistematizados sobre as Jornadas em Teresina, a reportagem publicada no site do G1 em 15 de junho de 2013 fornece uma ideia do teor do protesto. Conforme reportagem, estudantes articularam nas redes sociais um protesto pacífico para o dia 20 de junho de 2013, na mesma data em que protestos ocorreriam em outras cidades. Na convocação feita no Facebook, os organizadores ressaltaram que a proposta da manifestação era geral, contra tudo o que estava errado, incluindo transporte público, sistema de saúde, segurança e infraestrutura. Nas palavras de João Thorlief, um dos organizadores da manifestação citado na reportagem, "O protesto é para mostrar que o povo está indignado e quer mudanças gerais" (G1, 15/6/2013). A reportagem também reproduz a página do Facebook em que o protesto foi convocado. Na página os organizadores pedem para que os manifestantes utilizem a bandeira do Brasil, o que já indica o teor nacionalista que sobressaiu nos protestos posteriores do ciclo.

Os protestos persistiram nos anos seguintes. O discurso anticorrupção e de rechaço ao PT destacou-se em alguns deles. Vários foram liderados por organizações políticas de cunho liberal na economia e conservador nos costumes, tais como o Vem Pra Rua (VPR) e o Movimento Brasil Livre (MBL) (Gohn, 2018).

Dentre as reivindicações no ciclo de 2011 a 2016, Tatagiba e Galvão (2019) identificaram, em primeiro lugar, queixas dirigidas ao governo e ao sistema político, seguidas por demandas relativas a salário, trabalho e condições de vida nas cidades. Notase que as categorias governo e sistema político concentram reclamações ligadas principalmente aos problemas no funcionamento da democracia e ao petismo.

Como o objetivo do artigo não é examinar todo o ciclo, pois os protestos têm variações importantes, interessa aqui abordar as pautas do que comumente se associa a 
Junho de 2013. Em 2013, a principal queixa dos manifestantes referiu-se ao governo e ao sistema político, seguida de perto pelas reivindicações ligadas às condições de vida e, em menor escala, por reivindicações referentes a salários e condições de trabalho (Tatagiba e Galvão, 2019, p. 86).

Tatagiba e Galvão (2019) também mostram a diversidade de atores presentes nos protestos. Os grupos sociais tradicionalmente mais mobilizados, a exemplo dos trabalhadores, são os que mais se fizeram presentes nas ruas entre 2011 e 2016. Esses dados indicam a presença de organizações tradicionais, o que vai contra uma certa interpretação de que Junho de 2013 tenha reunido atores sociais novos cujas características eram a autonomia e a horizontalidade, qualidades mais próximas dos coletivos, o grupo classificado em sétimo lugar no quesito presença nos protestos, de acordo com o trabalho de Tatagiba e Galvão (2019). O trabalho das autoras foi feito com base em um banco de dados construído a partir das informações do jornal Folha de $S$. Paulo, expressando, por conseguinte, uma visão dos protestos centrada em grandes capitais do Sudeste. No entanto, o trabalho pontua a variedade de pautas e atores das Jornadas, ajudando a compreender as relações entre os coletivos e os protestos de Junho de 2013.

Logo, trata-se de um ciclo de protestos com variações importantes entre eles e dentro deles. A interpretação dos protestos como se fossem blocos homogêneos reduz a compreensão da sua diversidade. Por exemplo, em Junho de 2013 já estavam presentes membros de partidos e pautas mais à direita (como as que ressaltavam o fim da corrupção com um discurso moral). Para Alonso (2017, p. 52):

Não era um "todos contra tudo o que está aí". Havia dominâncias de pauta em cada setor da mobilização. Autonomistas e socialistas se situaram à esquerda do governo do PT, com agenda reformista, mais e melhores políticas públicas e expansão de direitos. O setor patriota ia do liberalismo (a favor do Estado enxuto e eficiente "padrão Fifa") ao conservadorismo (pró-ditadura militar), com foco no rechaço a instituições políticas, políticos e partidos, e na identificação do PT com a corrupção, via Mensalão ("Corruptos").

Em meio a essa proliferação de demandas e críticas ao sistema político, ocorreram as eleições de 2014, em que Dilma Rousseff (PT) foi reeleita. Logo em seguida, sua vitória foi questionada pelo adversário, Aécio Neves (PSDB). Seguiram-se denúncias de corrupção que evidenciavam o ativismo político-judicial e a seletividade da mídia brasileira (Feres Junior e Sassara, 2016). Esses fatores ajudaram a enfraquecer o governo, fortalecendo o PMDB (Partido do Movimento Democrático Brasileiro, depois MDB, Movimento Democrático Brasileiro) no Congresso Nacional, o que culminou com a eleição de Eduardo Cunha para a presidência da Câmara dos Deputados em 2015. Foi este então deputado pelo PMDB do Rio de Janeiro quem deu início ao processo de impeachment da presidenta Dilma Rousseff, levando seu vice, Michel Temer, ao posto de presidente do Brasil, em agosto de 2016. 
No âmbito internacional, em meados de 2010 grandes protestos ocorreram em outros lugares do mundo, como as jornadas da Praça Tahir no Egito, o Occupy Wall Street nos Estados Unidos e os Indignados na Espanha. Pleyers e Glasius (2013) explicam que esses e outros ativismos pós-2010 têm em comum infraestrutura de redes e reuniões, que facilita a rápida difusão de slogans, repertórios de ação e significados; os processos de globalização, que impactam de forma semelhante a geração de ativistas; e demandas e identidade centradas em três conceitos interconectados: democracia, justiça social e dignidade.

Conforme Bringel e Pleyers (2015), as mobilizações brasileiras compartilham algumas formas de expressão, ação e organização comuns a muitos movimentos contemporâneos, pois estão associadas, no espaço, a uma nova geopolítica da indignação global e, no tempo, a uma ruptura com ciclos políticos, sujeitos, práticas e concepções. Mas o Brasil tem particularidades que merecem atenção. Segundo Bringel (2013), enquanto na Europa e nos Estados Unidos a defesa era por direitos conquistados historicamente, no Brasil a reivindicação era por novos direitos ou a concretização daqueles já reconhecidos. Ademais, não houve difusão permanente e sistemática dos repertórios de ação para fora do Brasil. E também, se distanciando da articulação do local com o global, no Brasil a escala de ação principal foi a nacional. Por fim, no Brasil, as manifestações variaram em cada cidade e expressavam também demandas particulares e críticas às políticas local e regional.

\section{Os coletivos e a descrença nos partidos}

Apesar da diversidade das organizações que se definem como coletivos, em geral a literatura entende os coletivos como organizações políticas fluidas, horizontais e autônomas (Maia, 2013; Vommaro, 2015; Gohn, 2017). Conforme esse tipo de interpretação, nos coletivos não haveria um líder autorizado a falar em nome dos demais, a liderança seria compartilhada por todos. As decisões seriam tomadas de forma horizontal, mediante a livre expressão dos seus membros. Os jovens se identificariam com os coletivos pois eles seriam diferentes das formas de organização política que repudiam: partidárias, centralizadas, hierárquicas e burocráticas (Gohn, 2017). Em sentido complementar, segundo Vommaro (2015), os coletivos rechaçam o vínculo com partidos políticos, sindicatos ou igrejas, pautando a luta de forma direta, sem a necessidade de mediadores. Nesse sentido, eles seriam novas modalidades de organização coletiva e de participação política com atuação fora das vias institucionais tradicionais (Vommaro, 2015).

No entanto, é preciso problematizar essas características como se fossem compartilhadas por todos os coletivos ou ainda como se fosse compulsório adotá-las enquanto critério para classificar uma organização como um coletivo. A autonomia e a horizontalidade são mais próximas dos coletivos que atuam dentro das universidades, defendendo direitos, por exemplo, para mulheres, negros e LGBTTs. 
Conforme o entrevistado do Coletivo $\mathrm{H}$, que atua dentro da universidade: "(...) $\mathrm{O}$ coletivo serve para compartilhar suas ideias, decidir junto, coletivo, sem ninguém mandando, nem partido e nem líder". Nesse sentido o coletivo seria distinto de organizações hierárquicas em que os membros têm pouco espaço para compartilhar suas conviç̧ões e propostas, sendo induzidos a seguir decisões superiores. O coletivo teria caráter horizontal.

Ainda assim não é possível simplificar a organização de coletivos assumindo como único critério a inexistência de hierarquias: às vezes elas existem, às vezes não. Por exemplo, um membro do Coletivo Universitário C ligado a um movimento estudantil explica:

\begin{abstract}
Então, não existe uma hierarquia dentro do nosso coletivo. A gente se organiza através das nossas instâncias, dependendo de onde a gente tem um trabalho, um núcleo, a gente tem um núcleo de movimento estudantil na universidade (...). Como a gente é uma organização nacional, a gente tem esses núcleos dependendo de onde é o trabalho que a gente está fazendo e a gente se organiza em instâncias estaduais, municipais e as instâncias nacionais, e uma segue a outra.
\end{abstract}

Ou seja, existe hierarquia entre as esferas de decisão, embora esta não seja explicitamente admitida ou praticada na esfera local. Outro coletivo universitário (P) destaca a necessidade de organização para que as propostas do coletivo sejam concretizadas. Para ele, "o coletivo vai se pautar em divisão de tarefas, em programa político, em tática, estratégia, tudo isso de forma coletiva porque sozinhos nós não conseguimos atingir os objetivos maiores que a gente acredita ser necessário atingir". Logo, a hierarquia pode acontecer em determinadas situações.

Nota-se que, dentre os 21 coletivos entrevistados para o presente artigo, sete deles são ligados a partidos políticos: Partido Socialismo e Liberdade (PSOL), Partido Comunista Revolucionário (PCR), Partido Comunista do Brasil (PCdoB) e Partido Comunista Brasileiro (PCB) (coletivos do A ao G). Para alguns deles a hierarquia é mais presente, enquanto para outros essa questão é menos mencionada. Ainda assim cabe entender o que significa a horizontalidade e a autonomia nos coletivos, inclusive os partidários.

Quando falam de autonomia, os coletivos se referem à independência em relação à forma tradicional de partidos e de outras instituições com pouco espaço para exposição de ideias e tomada de decisões de forma compartilhada por todo o grupo. Ainda que pertencentes a partidos hierárquicos, os coletivos tentam se distanciar daquilo que consideram ultrapassado, como a vinculação a normativas centrais. Logo, a autonomia não é ausência de relações hierárquicas, mas sim uma outra forma de decidir, pautada pela importância da horizontalidade.

A horizontalidade pode ser aplicada em toda a organização ou em parte dela que se assume como coletivo. Por exemplo, um coletivo de mulheres vinculado a um partido 
mais centralizado pode ter mais horizontalidade nas decisões ali formuladas, ainda que outras discussões sigam diretrizes centrais. Embora a horizontalidade possa não existir, ela é almejada por parte dos coletivos, mesmo naqueles ligados a partidos.

Ainda que uma parcela dos coletivos seja vinculada a partidos, o caráter apartidário e/ou o antipartidário estão presentes em muitos dos seus discursos. No primeiro caso, conforme o discurso dos membros dos coletivos, é permitido que os membros sejam de partidos, no entanto, as orientações partidárias não devem sobressair em meio às decisões. Por exemplo, quando questionado se era permitida uma pessoa com vinculação partidária dentro do coletivo, um coletivo que atua em prol de direitos para estudantes negros (K) afirmou que não haveria problema, "desde que ela não queira se expressar aqui da mesma forma que ela faz dentro do partido".

Para os antipartidários entrevistados, por sua vez, os partidos retiram a autonomia dos indivíduos, tolhendo suas liberdades de pensar e agir, por isso eles devem ser rechaçados, ao menos dentro da organização. Conforme um entrevistado (Coletivo N),

ele [o coletivo] tem total autonomia com relação aos partidos políticos e a questão dos partidos políticos não cabe a nós debatê-la (...) mas as pessoas que têm liberdade de organização política para se organizar em um partido, se elas desejarem, então existe algumas pessoas que se organizam em partido mas são instâncias diferentes, que a gente tenta ao máximo manter a nossa autonomia a essas outras organizações.

As críticas aos partidos expressam a descrença em relação a estes disseminada em toda a sociedade. Conforme dados do Latinobarômetro ${ }^{4}$, de 1995 a 2017, o apoio aos partidos políticos vem caindo entre os brasileiros desde 2011: em 2010, 40\% dos brasileiros entrevistados não tinham nenhuma confiança nos partidos, número que chegou a $72 \%$ em 2017. No mesmo sentido, a porcentagem daqueles que têm alguma confiança no Congresso brasileiro também vem caindo: em 2010 eram 36\%, passando para 9\% em 2017, enquanto a resposta "nenhuma confiança" aumenta desde 2011 (20\% dos entrevistados afirmaram em 2010 que não tinham nenhuma confiança no Congresso, enquanto em 2017 foram 60\%).

Não obstante, ainda nesse quesito não se deve admitir generalizações, pois existem coletivos ligados a partidos políticos, como já demonstrado na descrição dos coletivos entrevistados. Um outro exemplo confirma essa aproximação: dentre as principais tendências do Partido Socialismo e Liberdade (PSOL, partido político brasileiro à

\footnotetext{
4 O Latinobarômetro reúne um amplo estudo sobre opinião pública. São aplicados anualmente por volta de 20 mil questionários nos países da América Latina (Argentina, Bolívia, Brasil, Colômbia, Costa Rica, Chile, Equador, El Salvador, Guatemala, Honduras, México, Nicarágua, Panamá, Paraguai, Peru, República Dominicana, Uruguai e Venezuela, com exceção de Cuba). A série histórica anual disponível no site do projeto (<http://www.latinobarometro.org/lat.jsp>) se inicia em 1995. São disponibilizados os dados até 2017, excetuando os anos de 1999 e 2012. Em cada ano são entrevistadas por volta de 1.200 pessoas de cada país.
} 
esquerda no espectro político) estão o Coletivo Resistência Socialista, o Coletivo Primeiro de Maio (tendência oriunda do Coletivo Rosa do Povo), Coletivo Rosa Zumbi e Coletivo Liberdade Socialista ( $C S L$ ), que se fundiu ao Socialismo Revolucionário para formar a corrente Liberdade, Socialismo e Revolução. Cabe ressaltar que mesmo alguns coletivos ligados a partidos criticam a forma de decisão hierárquica e centralizada por vezes presentes nos partidos: a proposta deles é aproximar os membros das decisões.

Em um contexto de descrença nas instituições partidárias e parlamentes, os coletivos se apresentam como uma opção de organização política mais próxima das necessidades da população. Essa ideia aparece na fala do Entrevistado $\mathrm{H}$ : "parece que o coletivo é um nome que aproxima mais as pessoas, sabe? Ele quebra um pouco daquela barreira burocrática de instituição. Acho que consegue atrair e chamar mais atenção, e isso faz com que as pessoas participem do coletivo". Logo, nos coletivos haveria uma tentativa de construção de práticas mais genuínas, mais próximas do povo e mais compartilhadas entre os membros, ainda que nem sempre passíveis de serem concretizadas. Tais práticas estariam distantes do que eles consideram negativo em política: hierarquias que se traduzem em falta de oportunidades de exposição e de decisão por parte de todos os membros.

Em síntese, não é possível considerar comuns características que vários coletivos declararam, como horizontalidade e autonomia, ainda que alguns deles defendam tais práticas como superiores. Tilly (2010) afirma que os movimentos sociais não podem ser considerados atores homogêneos. No mesmo sentido, Melucci (2001) ensina que as ações coletivas são heterogêneas, ou seja, são múltiplas, variáveis e nelas se entrelaçam heranças do passado com particularidades do presente. Nota-se que horizontalidade e autonomia, assim como a fluidez, eram características atribuídas aos movimentos sociais que atuavam na Europa e nos Estados Unidos em meados das décadas de 1960 e 1970, considerados à época como novos (Melucci, 1989).

A recusa aos partidos e organizações políticas tradicionais não faz parte somente dos coletivos. Bringel $(2013,2017)$ entende que as mobilizações ao redor do mundo nos últimos anos expressam uma indignação global marcada pela rejeição aos sistemas políticos, aos partidos tradicionais e às formas convencionais de organização política. Ainda conforme o autor, associados a essas críticas, os participantes dessas mobilizações defendem a horizontalidade, a negação da representatividade e o rechaço a lideranças políticas formais. Logo, a recusa às organizações tradicionais pelos coletivos deve ser entendida dentro de um movimento global.

Urbinati (2016) ajuda a compreender essa recusa por meio do conceito de "revolta contra corpos intermediários". Conforme a autora, as democracias consolidadas ou ocidentais estão em um processo de mudança significativa que tem relação com a crise econômica e com o impacto da internet. Em uma espécie de "revolta contra corpos intermediários", os cidadãos se opõem aos partidos políticos e ao jornalismo profissional, instituições centrais nos governos representativos dos dois últimos séculos. O processo de 
simplificação horizontal da participação que essa revolta gerou estabelece o que a autora chama de democracia representativa de transmissão ao vivo. Nela, os cidadãos querem interagir com os líderes por meio da internet, sem os partidos políticos. Há um desejo de monitorar e controlar instituições e líderes, em vez de autogoverno.

Certamente a presença de tais características da democracia contemporânea não significa o desaparecimento dos partidos ou da imprensa institucional, mas ajuda a entender organizações como os coletivos. O discurso dos coletivos e a novidade trazida pelo termo também demarcam o distanciamento em relação às organizações tradicionais. A adoção do nome coletivo é uma resposta à descrença em relação à política parlamentar, ao mesmo tempo em que impulsiona essa descrença. Nesse sentido, eles fazem parte dessa revolta dos corpos intermediários, pois negam partidos e instituições tradicionais, ao mesmo tempo em que podem estar vinculados a estes.

\section{Relações entre as Jornadas de Junho e o crescimento de coletivos}

A nomenclatura "coletivo" não é nova. Tampouco o são as organizações que se intitulam dessa maneira. Um dos coletivos mais famosos, o Combahee River, foi uma organização negra feminista ativa em Boston de 1974 a 1980, que chamava a atenção para o fato de o movimento feminista branco não estar contemplando as necessidades das mulheres negras. No Brasil, a professora e ativista Lélia Gonzalez fundou em 1983, com outras mulheres negras, o Nzinga, coletivo com base no Rio de Janeiro. Logo, não se trata de uma novidade. Ademais, as lutas feminista e antirracista, típicas dos coletivos universitários apresentados neste artigo, já eram bandeiras dos coletivos mais antigos. Inclusive os coletivos estavam presentes nas Jornadas, segundo Tatagiba e Galvão (2019).

No entanto, essa forma de organização vem crescendo. Conforme pesquisa realizada em todas as páginas de coletivos cadastradas no Facebook (725), a maior parte deles foi criada entre os anos de 2012 e 2016 (65,5\%) com pico em 2016 (16,7\%). É preciso ponderar esses dados já que o acesso à internet também cresceu nos últimos anos. Desde 2004, o acesso à rede nos domicílios brasileiros por meio de microcomputadores vem aumentando, variando de 6,3\%, em 2004, a 57,8\%, em 2015 (IBGE, 2016). Logo, o acentuado número de coletivos com páginas na internet criados nos últimos anos não está somente relacionado à adoção desse termo e dessa forma de organização, mas também ao crescimento do uso da internet, possibilitando assim a criação de páginas.

Mas os dados do Facebook coincidem com o ano de criação dos 21 coletivos pesquisados por meio de entrevistas qualitativas. Conforme as entrevistas, a maior parte dos coletivos foi criada entre os anos de 2011 e 2016, sendo que cinco deles foram criados em 2016.

Tanto a relação entre a criação dos coletivos e as Jornadas de Junho de 2013 quanto a relação deles com as ocupações estudantis ocorridas em 2016 em escolas e universidades, como a Universidade Federal do Piauí, foram apontadas nas entrevistas. 
Conforme os entrevistados que citaram as Jornadas de Junho, nos protestos eles entraram em contato com o conceito e a ideia de coletivos, e depois disso resolveram criar ou transformar as organizações nas quais já atuavam em coletivo.

Três relatos a seguir demonstram como, por vias distintas, os coletivos foram se constituindo. Um membro de um coletivo ligado a partido político (A) relatou que, logo após as Jornadas de Junho, núcleos do seu partido se juntaram formando um grande coletivo. Outro membro de coletivo ligado a partido político (B) explicou que a corrente da juventude do partido em que milita se separou em meados de 2013, formando dois coletivos distintos. Embora adote o nome de coletivo, a organização em que o entrevistado atua é ligada a um partido político criado em meados dos anos de 1980, que hoje possui dentro de si correntes formadas por jovens e se definem como coletivos. Os partidos têm um importante papel na formação de militantes políticos. Conforme o entrevistado do Coletivo B: "A aproximação [com a ideia de coletivo] foi através de formações sobre política. (...). Formação do partido voltada para a questão dos movimentos sociais".

Já um entrevistado de coletivo que defende direito à cidade (I) explicou que quis atuar em uma organização política depois das Jornadas de Junho. Conforme seu relato:

(...) a decisão de aceitar entrar num coletivo político (...) foi por conta de que eu não conseguia mais compreender como que tanta gente passa fome pra alguém ter dinheiro (...) foi quando eu conheci essa minha amiga nas manifestações contra o aumento e aí de lá pra cá foi só fortalecendo esse vínculo, e na universidade foi que fortaleceu ainda mais.

A importância da universidade como local em que se entra em contato com os coletivos, passando a atuar neles, também foi revelada por outros entrevistados. Conforme um membro de um coletivo em prol da população LGBTT (M): "(...) como a gente passa por algumas espécies de militância dentro da universidade, já sabia que tinha vários coletivos e a gente pensou em trazer um coletivo que trabalhasse sobre gênero e sexualidade". Esse mesmo entrevistado começou a atuar no coletivo por volta de 2013. Com um histórico parecido acerca de como passou a atuar em um coletivo, o entrevistado do coletivo da área ambiental (P) explicou que o contato aconteceu em 2011, na universidade, mas depois a organização se ampliou.

Já o coletivo que atua em prol de mais direitos para os estudantes negros (K) destaca que a organização foi criada por alunos cotistas que entraram na universidade e experienciaram a necessidade de políticas que garantissem direitos para a população estudante negra.

Logo, não há uma gênese em comum, mas sim a adoção do nome e de práticas consideradas mais genuínas, distantes das formas de organização tradicionais de partidos e parlamentos, que não dariam espaço para que todos compartilhassem suas ideias. Conforme parte dos entrevistados, tais organizações teriam se distanciado dos anseios da 
população, daí a necessidade de se organizarem e atuarem de forma mais próxima, sob o formato de coletivos.

A defesa de que os coletivos devem estar mais próximos do povo se mistura com as críticas aos partidos, considerados mais distantes da população. Conforme um coletivo anticapitalista (N): "A gente não tem um partido, a gente não tem nada. Então nosso lugar é a favor do povo e [que] aquilo fique melhor pra todos". Percebe-se que estar ao lado dos partidos seria sinônimo de se afastar do povo. Inclusive esse coletivo foi contra a presença de partidos nas ocupações da universidade em 2016. Conforme seu relato:

Então, a gente às vezes tá nesse processo de disputa, porque a gente sabe que a galera partidária, eles são muitas vezes direcionistas, tentam direcionar tudo, tudo, tudo pelo modo e o princípio deles. Pelo modo partidário deles (...) Eles não tão querendo um bem maior, um bem comum, é só promoção deles e o quanto eles são oportunistas.

Na concepção desse entrevistado, os partidos são organizações que promovem interesses próprios. No mesmo sentido, conforme outro entrevistado de um coletivo de artes (T), o problema dos partidos "(...) foi que a luta pelo poder político, ela sempre se sobrepôs à luta pela humanidade, à luta pela emancipação da humanidade".

As entrevistas revelaram que a descrença nos partidos tem relação com a decepção com o Partido dos Trabalhadores. Por exemplo, conforme o relato de uma entrevistada oriunda de um coletivo que defende direitos para estudantes negros (K): "o governo federal quando era do PT apenas ratificava o interesse da burguesia nacional". A crítica ao PT é comum entre os coletivos, afinal: "[o] PT, que era aquele partido que a gente sabe como é, a gente meio que se sentiu traído por esse governo" (Entrevistada A). Conforme outro entrevistado, o PT "(...) não chamou o povo pra lutar contra o golpe e o que se observa agora, inclusive, [são] alianças entre os setores maiores do Partido dos Trabalhadores e outros partidos" (Entrevistado O). Percebe-se também nas entrevistas uma decepção com o fato de o Partido dos Trabalhadores (PT) não ter feito reformas estruturais e profundas com o intuito de reduzir a desigualdade social, como se esperava de um partido mais à esquerda.

Como explica Tatagiba (2014), o Partido dos Trabalhadores firmou sua identidade como um partido que não corrompe e nem é corrompido. Em 2005, as denúncias de Mensalão do PT colocaram em risco o segundo mandato do ex-presidente Lula. Em 2013 o tema reaparece como uma das principais críticas presentes nas Jornadas. E em 2014 as denúncias de corrupção envolvendo a Petrobras quase custaram a recondução de Dilma Rousseff à presidência: "Ou seja, o frame do 'combate à corrupção' encontra forte ressonância popular, o que o tornou uma bandeira poderosa de mobilização à esquerda e à direita ao longo desses trinta anos. E nas mobilizações de Junho não foi diferente". (Tatagiba, 2014, p. 44). 
Tatagiba e Galvão (2019) demonstram que os protestos expressaram insatisfações de dois setores: daqueles que queriam avanços nas reformas promovidas pelo PT e daqueles que buscavam restaurar o status quo. Nesse sentido é possível perceber que o discurso antipetista passa a ser compartilhado tanto pela esquerda, insatisfeita com as limitações do PT, quanto pela direita, que não concordava com as diretrizes do projeto petista.

Embora as críticas ao PT possam ser compartilhadas, todos os coletivos entrevistados se definiam como à esquerda. A organização em forma de coletivo permite ficar imune às críticas de que são alvo as organizações parlamentares e partidárias tradicionais ao mesmo tempo em que preserva valores da esquerda, como a igualdade e o bem comum. O coletivo remete a uma organização com menos hierarquias e que preserva fins éticos. Essa é uma das explicações para o termo ter sido adotado por organizações à esquerda, ainda que possam existir algumas organizações à direita que se denominem dessa forma.

Assim como ocorreu nas entrevistas dos membros dos coletivos, nos protestos o discurso antipetista tinha relação com as críticas aos partidos. Conforma Tatagiba (2014, p. 50), nos protestos "um dos alvos principais das hostilidades era o militante petista, evidenciando uma forte associação entre apartidarismo e antipetismo". Em outro trabalho, Tatagiba e Galvão (2019) distinguem as críticas ao sistema político do antipetismo. Conforme as autoras (2019, p. 87): "é importante considerar que o descrédito na política e nos políticos é maior do que o antipetismo (...) e anterior a $2013(\ldots)$ ". Mas ambos os fenômenos parecem ter se misturado em protestos posteriores a 2013.

Percebe-se nas reivindicações dos manifestantes de Junho de 2013 pontos em comum com os dos membros dos coletivos entrevistados: em ambos os casos expressamse uma descrença nos partidos tradicionais e a crítica ao governo do PT. Em Junho e em protestos similares, os manifestantes aprenderam e alimentaram discursos antipartidários e hostis a organizações políticas tradicionais. A recusa a tais instituições tem relação com a própria autodenominação como coletivo e não como movimento social, organização ou mesmo partido, ainda quando sejam ligados a estes.

Esses achados vão na direção da literatura que considera que as Jornadas não tiveram impacto somente no sistema político institucional ou eleitoral, mas, de forma ampla, contribuíram para uma reconfiguração do ativismo social (Perruso, 2014; Bringel e Pleyers, 2015). Junho de 2013 incentivou novos atores a se organizarem politicamente, utilizando discursos e repertórios aprendidos nas Jornadas. Ou seja:

(...) as mobilizações massivas de Junho de 2013 produziram uma abertura societária no Brasil. Emergiram novos espaços e atores que levaram a um aumento da conflitualidade no espaço público e a um questionamento dos códigos, sujeitos e ações tradicionais que primaram no país durante as últimas duas décadas (Bringel e Pleyers, 2015, p. 4). 
Conforme Bringel e Pleyers (2015), essa nova geração de militantes não possui as mesmas experiências, visões de mundo e relações com o campo popular-democrático da geração dos anos 1970 e 1980. Suas práticas e expressividades buscam se distanciar dos movimentos e partidos mais convencionais e dos repertórios de mobilização guiados por bandeiras e lemas previamente definidos.

Dentro dessas mobilizações estariam as ocupações das escolas pelos secundaristas e universitários ao final de 2015 e em 2016 em todo o Brasil (Palácio, 2018). Os estudantes protestaram principalmente contra o fechamento de escolas (ou a reorganização do sistema estudantil conforme o projeto do ex-governador de São Paulo, Geraldo Alckmin) e contra a "PEC do teto de gastos" (Projeto de Emenda Constitucional 241, que limitou o crescimento das despesas do governo brasileiro durante 20 anos). Isso se explica porque, além de incentivar mais manifestações, Junho de 2013 foi responsável por socializar politicamente novos atores. Conforme Perruso (2014, s.p.):

Um bom número de cidadãos está se socializando politicamente apenas desde junho de 2013, se definindo enquanto esquerda, centro ou direita (e seus diversos matizes) e mesmo construindo, por meio da experiência coletiva nas ruas, novos balizamentos para essa classificação político-ideológica.

A relação entre os protestos e a formação de novos atores sociais é apontada pelos teóricos dos movimentos sociais. Conforme Melucci (1989), o momento de visibilidade dos movimentos sociais renova a solidariedade, facilitando a criação de novos grupos e o recrutamento de novos militantes. Junho foi um movimento de visibilidade. Tarrow (2009) explica que os ciclos de protestos difundem quadros interpretativos e modelos de ativismo, incentivando mais mobilização social. Nesse sentido, os efeitos dos ciclos vão muito além dos objetivos visíveis do movimento: "eles deixam atrás de si uma ampliação permanente na participação, na cultura popular e na sua ideologia" (Tarrow, 2009, p. 25).

Em Junho e em espaços de militância daquele período, parte dos entrevistados entrou em contato com a ideia de coletivos e começou a atuar neles, assim como conheceu e difundiu um certo rechaço a organizações hierárquicas, tais como determinados partidos.

Os estudos sobre formação de identidade coletiva ajudam a entender esse processo. Conforme Melucci (1989), a identidade coletiva não implica necessariamente estruturas cognitivas coerentes ou unificadas, mas é construída por meio da interação entre os atores. Os protestos foram um momento de interação. Fominaya (2010) explica que a participação conjunta em protestos gera laços entre ativistas e constrói uma história de memórias compartilhadas que pode sustentar movimentos sociais, mesmo em períodos de baixa atividade ou de suspensão destes.

Nesse sentido, Junho e os protestos posteriores incentivaram mais coletivos. Notase que os coletivos já existiam antes e estavam presentes inclusive nos protestos de 2013. Mas os dados mostram que as Jornadas incentivaram mais mobilizações que se caracterizaram pelo distanciamento discursivo com relação a organizações tradicionais tais 
como partidos, defendendo práticas mais horizontais, inclusivas e próximas à população. Tais organizações reproduzem e alimentam o discurso antipartidário e antissistema presente nas Jornadas.

\section{Considerações finais}

Este artigo examinou algumas relações entre as Jornadas de Junho de 2013 e o crescimento de organizações chamadas "coletivos". Embora não seja possível estabelecer uma definição que abarque todos os tipos de organizações políticas que se definem como coletivos, pode-se constatar que, em comum, o discurso dos coletivos aponta para práticas e nomenclaturas que demarcam distância tanto das instituições parlamentares quanto do modo de articulação política dos partidos e outras organizações formais, consideradas hierárquicas.

Para se contraporem a esse modelo, os coletivos se definem como mais horizontais e autônomos, embora tais caraterísticas não necessariamente estejam presentes. Ademais, há nuances entre os coletivos que impedem generalizações capazes de contribuir para o rechaço de organizações políticas que não se encaixam em determinados padrões.

O artigo explorou como as Jornadas promoveram a socialização política dos jovens e como incentivaram o surgimento de mais organizações políticas que reproduzem as críticas presentes nas Jornadas, e respondem a elas, a exemplo daquela direcionada aos partidos e às organizações políticas tradicionais. Junho de 2013 também deixa como marca a expansão do ativismo juvenil, que busca, ainda que discursivamente, reinventar a prática política com relações mais horizontais. Nesse sentido, o artigo contribui para a literatura que investiga os legados das manifestações, para além das mudanças institucionais.

Por fim, é importante chamar a atenção para possíveis consequências do discurso, presente nos coletivos, de distanciamento das instituições parlamentares consideradas centralizadoras e ineficientes. Tais instituições são centrais na democracia moderna. 0 rechaço a elas pode contribuir para o crescimento de organizações e propostas que se dizem novas e que atuam por fora das regras democráticas.

\section{Referências bibliográficas}

Alonso, A. "A política das ruas? Protestos em São Paulo de Dilma a Temer". Novos Estudos Cebrap, São Paulo, p. 49-58, 2017.

AMADOR, A.; CASTRO, E. "O coletivo (com preguiça): encontros, fluxos, pausas, artes". Interface, Botucatu, vol. 20, no 56, p. 267-280, 2016.

Augusto, A; RosA, P. O.; Resende, P. E. R. "Capturas e resistências nas democracias liberais: uma mirada sobre a participação dos jovens nos novíssimos movimentos". Revista Estudos de Sociologia, Araraquara, vol. 21, no 40, p. 21-37, 2016. 
BARDIN, L. Análise de conteúdo. Lisboa: Edições 70, 2006.

BORDT, R. L. "Show alternative ideas become institutions: the case of feminist collectives". Non Profit and Voluntary Sector Quarterly, vol. 26, no 2, p. 132-155, 1990.

Borelli, S.; АвовoreirA, A. "Teorias/metodologias: trajetos de investigação com coletivos juvenis em São Paulo/Brasil". Revista Latinoamericana de Ciencias Sociales, Manizales (Colombia), vol. 9, no 1 , p. 161-172, 2011.

BRIngeL, B. Miopias, sentidos e tendências do levante brasileiro de 2013. In: BRINGEL, B.; Domingues, J. M. (orgs.). As Jornadas de Junho em perspectiva global. Rio de Janeiro: Netsal; Iesp, p. 16-29, 2013.

Movimientos sociales y la nueva geopolítica de la indignación global. In: BRINGEL, B.; PLeYers, G. (eds.). Protesta e indignación global: los movimientos sociales en el nuevo orden mundial. Ciudad Autónoma de Buenos Aires: Clacso; Rio de Janeiro: Faperj, p. 29-36, 2017.

Bringel, B.; PLeYers, G. "Junho de 2013... Dois anos depois: polarização, impactos e reconfiguração do ativismo no Brasil". Nueva Sociedad, Buenos Aires, vol. 259, p. 4-17, 2015.

CostA, D.; PAULON, S. "Participação social e protagonismo em saúde mental: a insurgência de um coletivo". Saúde em Debate, Rio de Janeiro, vol. 36, no 95, p. 572-582, 2012.

DAGNino, E. Sociedade civil, participação e cidadania: do que estamos falando?. In: MATo, D. (ed.). Políticas de ciudadanía y sociedad civil in tiempos de globalización. Caracas, Venezuela: FaCES, Universidad Central de Venezuela, 2004.

DESOUZA, S. "The strenght of collective processes: an 'outcome analysis' of women's collectives in India". Indian Journal of Gender Studies, vol. 19, no 3, p. 373-392, 2012.

Feres Junior, J.; SASSARA, L. "O terceiro turno de Dilma Rousseff". Saúde Debate, Rio de Janeiro, vol. 40, p. $176-185,2016$.

FerreirA, G. "Margeando ativismos globalizados: nas bordas do Mujeres Al Borde". Revista Estudos Feministas, Florianópolis, no 312, p. 207-218, 2015.

FominayA, C. "Collective identity in social movements: central concepts and debates". Sociology Compass, no 4, p. 393-404, 2010.

G1. "Estudantes de Teresina articulam protesto pacífico no dia 20 de junho", 15/6/2013. Disponível em: <http://g1.globo.com/pi/piaui/noticia/2013/06/estudantes-de-teresina-articulam-protestopacifico-no-dia-20-de-junho.html>. Acesso em: jan. 2018.

GoHn, M. G. Manifestações e protestos no Brasil. São Paulo: Cortez, 2017.

"Jovens na política na atualidade: uma nova cultura de participação". Caderno CRH, Salvador, vol. 31, no 82, p. 117-133, 2018.

IBGE. "Acesso à internet e à televisão e posse de telefone móvel celular para uso pessoal: 2015". Rio de Janeiro, 2016.

LATINOBARÔMETRO. Banco de dados: Latinobarômetro 2010, 2013 e 2015. Disponível em: <http://www.latinobarometro.org>. Acesso em: 4 maio 2018.

MAIA, G. L. "A juventude e os coletivos: como se articulam novas formas de expressão política". Revista Eletrônica do Curso de Direito da UFSM, Santa Maria, vol. 8, no 1, p. 58-73, 2013.

Melucci, A. "Um objetivo para os movimentos sociais?". Lua Nova, São Paulo, no 17, p. 49-66, 
1989.

. A invenção do presente: movimentos sociais nas sociedades complexas. Petrópolis: Vozes, [1982] 2001.

MesquiTA, M. R. "Cultura e política: a experiência dos coletivos de cultura no movimento estudantil". Revista Crítica de Ciências Sociais, Coimbra (Portugal), vol. 81, p. 179-207, 2008.

MORA, C.; Rios, M. "De política de representación a política de coalición? Posibilidades de movilización feminista en el Chile post-dictadura". Revista de la Universidad Bolivariana, Chile, vol. 8, no 24, p. 133-145, 2009.

PalÁcio, F. "Sob o céu de Junho. Após cinco anos do enigmático Junho de 2013, ainda cabem mais perguntas do que respostas". Portal da Revista Cult-UOL 11 jun. 2018. Disponível em:

<https://revistacult.uol.com.br/home/sob-o-ceu-de-junho-2013/>. Acesso em: ago. 2018.

PERRUSO, M. "As manifestações de Junho de 2013 e o horizonte dos movimentos sociais no Brasil". Anais do $38^{\circ}$ Encontro Anual da Anpocs. Caxambu, 2014.

Pleyers, G.; Glasius, M. "The global moment of 2011: democracy, social justice and dignity". Development and Change, vol. 44, nº 3, p. 547-567, 2013.

SAPRIEZA, G. "'Nos habíamos amado tanto'. Años revueltos. Mujeres, colectivos y la pelea por el espacio público". Revista Estudos Feministas, Florianópolis, no 23, p. 939-958, 2015.

SiqueirA, J. L.; LAGO, A. V. "Coletivo da música: um estudo sobre relações entre arte e saúde mental". Estudos Interdisciplinares de Psicologia, Londrina, vol. 3, no 1, p. 93-111, 2012. TARROW, S. O poder em movimento: movimentos sociais e confronto político. Petrópolis: Vozes, 2009.

TATAGiBA, L. "1984, 1992 e 2013: sobre ciclos de protestos e democracia no Brasil". Política \& Sociedade, vol. 13, no 28, p. 35-62, 2014.

Tatagiba, L.; Galvão, A. "Os protestos no Brasil em tempos de crise (2011-2016)". Opinião Pública, Campinas, vol. 25, no 1, p. 63-96, 2019.

TAvares, F. M. M.; RoRiz, J. H. R.; Oliveira, I. C. "As Jornadas de Maio em Goiânia: para além de uma visão sudestecêntrica do Junho brasileiro em 2013". Opinião Pública, Campinas, vol. 22, n 1 , p. $140-166,2016$.

Tilly, C. "Os movimentos sociais como política". Revista Brasileira de Ciência Política, vol. 3, p. 133$160,2010$.

URBinAti, N, "Uma revolta contra os corpos intermediários". Leviathan: Cadernos de Pesquisa Política, no 12, p. 176-200, 2016.

VALK, A. M. "Living a feminist lifestyle: the intersection of theory and action in a lesbian feminist collective". Feminist Studies, vol. 28, no 2, p. 303-332, 2002.

Vommaro, P. Juventudes y políticas en la Argentina y en América Latina: tendencias, conflictos y desafios. Argentina: Grupo Editor Universitário, 2015. 


\section{Abstract \\ Relations between collectives with the Journeys of June}

This article discusses political organizations called collectives and their relations with the cycle of protests known as the Jornadas de Junho (June Journeys) in 2013. As part of this exploratory research, we interviewed the members of 21 collectives throughout the city of Teresina and systematized 725 pages of information about the collectives documented on the social network Facebook. The results indicate that these collectives were created mainly in the last six years, and members of some of them identified the collectives as a form of political organization after the June Journeys. In addition to this relationship, the collectives criticize political parties and traditional organizations due to their hierarchies and inefficiency. Criticism of the government and parties were also common at the June Journeys. In opposition to this model of political organization, some collectives advocate more autonomous and horizontal practices. To understand the emergence of organizations after the protests, we review the literature of theorists of social movements. This text contributes to studies on social mobilization by analyzing the legacies of the June Journeys, such as incentives to engage in collectives.

Keywords: collectives; Journeys of June; antipartisanism

\section{Resumen}

Relaciones entre colectivos con las Jornadas de Junio

Este artículo aborda organizaciones políticas denominadas colectivos y sus relaciones con el ciclo de protestas conocidas como Jornadas de Junio de 2013. La investigación exploratoria entrevistó a miembros de 21 colectivos de la ciudad de Teresina y sistematizó informaciones de 725 páginas de colectivos registrados en la red social Facebook. Los resultados indican que los colectivos fueron creados principalmente en los últimos seis años, siendo que miembros de algunos de ellos conocieron la forma de organización política del tipo colectivo después de las Jornadas. Además de esa relación, los colectivos critican a partidos políticos y organizaciones tradicionales, por la presencia de jerarquías e ineficiencia de ellas. La crítica al gobierno y a los partidos también estaban presentes en las Jornadas. Justamente para contraponerse a ese modelo de organización política, algunos colectivos defienden prácticas más autónomas y horizontales. Para entender la emergencia de organizaciones después de las protestas se reanudan reflexiones de teóricos de los movimientos sociales. Este texto contribuye a los estudios sobre la movilización social mediante el análisis de legados de las Jornadas, como el incentivo a los colectivos.

Palabras clave: colectivos; Jornada de Junio; antipartidarismo

\section{Résumé}

Relations entre les collectifs avec les Journées de Juin

Cet article traite des organisations politiques dénommées collectifs et de leurs relations avec le cycle de manifestations connu sous le nom de Journées de Juin 2013. La recherche exploratoire a interviewé des membres de 21 collectifs de la ville de Teresina et a systématisé l'information de 725 pages de collectifs enregistrées sur le réseau social Facebook. Les résultats indiquent que les collectifs ont été créés principalement au cours des six dernières années et que certains membres ont connu la forme d'organisation politique de type collectif après les Journées. En plus de cette relation, les collectifs critiquent les partis politiques traditionnels et les organisations à cause de la présence de hiérarchies et de leur inefficacité. Les critiques du gouvernement et des partis étaient également présentes aux Journées. C'est précisément pour s'opposer à ce modèle d'organisation politique que certains collectifs préconisent des pratiques plus autonomes et horizontales. Pour comprendre l'émergence d'organisations après les manifestations, on reprend les concepts les théoriciens des mouvements sociaux. Ce texte 
contribue aux études sur la mobilisation sociale en analysant les héritages des Journées, tels que le soutien aux collectifs.

Mots-clés: collectifs, Journées de Juin, antipartisanisme

Artigo submetido à publicação em 4 de novembro de 2018. Artigo ressubmetido à publicação em 12 de junho de 2018. Versão final aprovada em 27 de setembro de 2019.

Opinião Pública adota a licença Creative Commons CC-BY. 